\title{
Actuar moralmente con sentido hermenéutico
}

\author{
Sergio Pérez Cortés
}

Pablo Lazo Briones, Charles Taylor. Hermenéutica, ética y politica.

México, Gedisa, 2016, 468 pp.

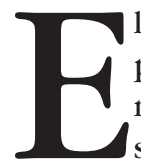

1 libro de Pablo Lazo Briones acerca de Charles Taylor puede ofrecer, para algunos de nosotros, un cierto número de sorpresas. Probablemente ciertos lectores, como yo, localizan al filósofo canadiense por sus importantes contribuciones en torno a G. W. F. Hegel y por sus concepciones acerca del llamado multiculturalismo. Pues bien, en el libro que nos ocupa a lo largo de más de 400 páginas, la imagen que resulta es la de un hermeneuta, mucho más próximo a Gadamer, Ricoeur o incluso al mismo Heidegger. No es desde luego que Hegel haya desaparecido súbitamente: está presente $-\mathrm{y}$ a ello se dedica el capítulo III- pero su intervención es matizada por motivaciones más profundas en Charles Taylor. Con esta corrección poseemos, pues, una percepción más precisa de uno de los filósofos más interesante de nuestros días.

El argumento central del autor es actual e importante: se propone ofrecer una conjunción entre ética y hermenéutica que sea una alternativa a las éticas formalistas de corte kantiano o procedimental. Digo "alternativa", porque fundamenta la acción moral en una autorreflexión sustantiva del agente acerca de sus propios valores, especialmente en su enfrentamiento con culturas que nos resultan ajenas. Frente a la diversidad cultural, ciertas éticas se colocan en actitud de etnocentrismo o simplemente de rechazo; una ética de raíz hermenéutica por el contrario se propone adoptar una actitud que no sea ni de apropiación, ni de manipulación, asumiendo a la vez una actitud crítica de sí misma a través de una comprensión de la otredad que sea dialógica y tolerante. En breve, se trata de alcanzar mediante la hermenéutica, criterios y directrices generales para la acción ética que descansen en la tolerancia teórica y práctica en el ámbito privado, público y en las relaciones interculturales.

Antes de entrar en lo vivo de la cuestión, permítaseme subrayar algunos aspectos formales de la obra de Pablo Lazo. El libro presenta una exposición clara y bien articulada de las tesis que se propone defender, incluidas aquellas 
que se refieren a autores que, como Heidegger, no tienen una reputación de transparencia. Esta claridad se debe, al menos en parte, a que a este trabajo le precede un libro previo sobre Charles Taylor del que el presente es continuación. De manera que ambos colocan a Pablo Lazo como uno de los conocedores más profundos en nuestro medio del filósofo canadiense. El libro tampoco se conforma con una mera exposición: con frecuencia nuestro autor enfrenta las críticas que han podido formularse tanto a la hermenéutica en general como al autor que defiende y en un cierto número de casos sugiere vínculos entre los filósofos contemporáneos que no siempre han recibido la atención que merecen. La investigación revela entonces un sentido profundo de la seriedad y de compromiso con nuestra disciplina.

Sería posible ofrecer diversas perspectivas acerca del libro que nos ocupa. La que me permito desarrollar aquí intenta destacar lo que quizá son los rasgos distintivos de una ética con sentido hermenéutico. A mi juicio, estos rasgos son tres: $a$ ) ser una ética de la acción; $b$ ) ser una ética de la acción dialógica, consigo mismo y con el otro; $c$ ) para establecer las orientaciones generales de la acción desde una consideración intercomunitaria. Veamos uno a uno.

Desde el punto de vista hermenéutico, el agente está siempre colocado en una posición determinada respecto al mundo en que actúa. La reflexión ética debe, por tanto, ofrecer una orientación para dicha acción práctica. Colocar a la acción como núcleo de la ética es adoptar una posición filosófica que distingue la hermenéutica de otras concepciones: de una parte, evita la supuesta neutralidad de ciertas éticas procedimentales y neokantianas que estiman que es posible alcanzar un observatorio neutro o bien puede establecerse formalmente una partición entre lo legítimo y lo prohibido antes de realizar cualquier acción humana. Para la ética hermenéutica, por el contrario, todo acto moral es indisociablemente reflexivo y práctico: ésta coloca al agente siempre en situación, es decir, debe realizar afirmaciones sustantivas tanto del concepto por el cual actúa, como en la valoración de otros estilos de vida. No está al alcance de un agente moral colocarse en un observatorio exterior desde el cual podría decidir arbitrariamente su curso de acción: "Hablar de una relación entre ética y hermenéutica [...] es hablar de dos dimensiones de una misma práctica de los sujetos en una comunidad dada" (p. 28). Una acción moral no es lo que acontece después de una reflexión solitaria, sino la unidad de una interpretación cuyas posibilidades son éticas, o bien, si se quiere, una acción ética que permite un acto interpretativo. En breve, esta ética no trata de establecer un marco normativo, formal y abstracto, al cual debería plegarse, por simple respeto al deber, cualquier acción humana.

De ahí la importancia que adquiere la categoría de "experiencia". "Experiencia" quiere decir que, puesto que no existe neutralidad en los principios que regulan las prácticas en las que se realiza la vida en común, entonces 
es indispensable un factor de interpretación de sí y del otro. "Experiencia" significa que el agente debe formarse un carácter para ocupar su sitio en una situación con significado en la que no hay reglas generales sino una deliberación surgida en el mismo contexto de la acción. Esta deliberación tiene, sin embargo, dos premisas: el agente no está constreñido, ni por la tradición a la que pertenece, ni por los valores que simplemente encuentra frente a sí. Este distanciamiento crítico es crucial porque abre un dominio de posibilidades éticas: la comprensión de la situación es un "existenciario", definido como un "poder ser", como "posibilidad". Ciertamente, el agente se compromete con los valores que pone en juego, pero esta comprensión tiene un carácter siempre abierto y no adopta ciegamente ni una cosa ni la otra. En una situación dada, todo criterio o fórmula que permita tomar una decisión que conduzca a la acción es susceptible de revisión y crítica. El agente no posee ninguna predisposición ética: sólo se hace "experto" a partir del enfrentamiento cotidiano de su "ser en el mundo" (para usar una expresión heideggeriana). De este modo, el agente es libre de crear, a través de su experiencia, su propia identidad que depende de su acción sobre sí mismo y sobre el otro.

Un segundo componente central de la acción ética con sentido hermenéutico es la afirmación de que el agente moral actúa en un contexto intersubjetivo. La ética hermenéutica se opone así a la idea de que un individuo aislado, cuyo único recurso es el apego formal a su propia razón, pueda encontrar pautas para orientar su acción. Por el contrario, ella afirma que el ser humano es un ser dialógico. Sin duda este carácter dialógico se explica porque la hermenéutica participa de ese movimiento que se ha dado en llamar el "giro lingüístico", que coloca al lenguaje como mediación absoluta para el ser humano. Sólo que aquí el lenguaje no es un simple "instrumento neutral" con el cual los seres humanos designan un mundo de cosas externas, sino aquello que mediante una interpretación otorga sentido a su relación con ese mundo. Para esta filosofía ninguna situación y ninguna acción puede ser inteligible si no es mediante alguna clase de interpretación. Hacer sentido de una experiencia cualquiera es mostrar la coherencia de algún significado, donde la expresión "hacer sentido" quiere decir proferir una interpretación. La significación de las cosas y de los sujetos sólo puede aparecer al interior de un "campo interpretativo", es decir, siempre en relación con la significación de otras cosas: "No hay estructura de las significaciones que no involucre simultáneamente una autointerpretación. Desde luego esto implica un círculo, porque no puede haber sino 'interpretaciones de las interpretaciones' y no hay ninguna verificación última formalizable capaz de romper este círculo" (p. 155).

Desde la perspectiva hermenéutica el individuo no decide en soledad el significado de su acción, porque el significado se obtiene sólo a través del diálogo con el otro, lo que implica alguna clase de reconocimiento mutuo. 
La comprensión que cada individuo puede alcanzar de sí mismo siempre está teñida por su finitud, es decir, por el hecho de que depende de una tradición que le constituye y de la cercanía con los otros. Si duda sobre la comprensión de una acción tiene una parte "intencional" propia al agente, pero no puede ser "expresiva" sino en una comunidad potencial de comunicación creada y recreada en el espacio público. Pero es justamente aquí donde reside su actitud de libertad de crítica: puesto que el lenguaje jamás escapa a la valoración, la única salida es buscar la "mejor interpretación". El ser humano no escapa al mundo de las interpretaciones pero en cambio erige su libertad eligiendo su interpretación: "Su comprensión es una disposición a sufrir transformaciones del ser, tener un ser "poroso" respecto al ser en el mundo, o dicho con una imagen, ser una existencia significativamente tejida al mundo" (p. 48). Y este carácter dialógico es lo que permite al agente hacer una "construcción de sí mismo". El diálogo lo interpela: es a la vez posibilidad del reforzamiento de algunas formas culturales propias y de su transformación mediante la capacidad de escuchar. Es aquí donde puede lograr lo que Taylor llama su "acción básica": el agente debe buscar una acción sin coerciones ni autoengaño que le sirva incluso para contrastar con otras acciones carentes de libertad, una acción "abierta" a la comprensión de un mundo de manera madura y libre.

Porque es también en el carácter dialógico donde aparece uno de los mayores riesgos: el encuentro con la diferencia puede conducir a la imposición de uno sobre el otro. El problema de la lucha por el reconocimiento es la tendencia al etnocentrismo. El agente debe mantener un diálogo con el otro porque la experiencia humana es una gama inmensa de posibilidades, pero corre el riesgo de convertirse en una empresa de colonización. A fin de evitar este riesgo, Taylor sugiere "una fusión de horizontes normativos", es decir, aceptar que nuestros juicios y acciones han sido o pueden ser transformados por la comprensión del otro.

$\mathrm{Y}$ esto nos conduce al tercer gran componente de la acción ética con sentido hermenéutico: la idea de que toda acción moral se lleva a cabo no solamente en un espacio público, sino en un territorio intercultural. La verdadera formación moral del agente se realiza cuando enfrenta un conjunto de valores y bienes alternativo al suyo, sea dentro de su propia cultura o, lo que es más probable, ante mundos culturales diferentes. ¿A qué se opone entonces la ética hermenéutica? A las éticas trascendentalistas o ahistóricas que parecen suponer que tendencialmente existe solo una forma posible de humanidad y una sola forma de racionalidad que le corresponda. Para esta ética, por el contrario, toda acción humana se desenvuelve en un mundo de posibilidades, contrastes y alternativas diversas ante las cuales el agente moral debe inevitablemente adoptar alguna posición. Se reconoce aquí una de las grandes motivaciones de la filosofía de Charles Taylor: su respeto a la 
diversidad cultural. Pero la oposición al etnocentrismo moral no descansa ahora en Hegel, sino en los principios hermenéuticos. La hermenéutica no ve el encuentro con otras culturas como un obstáculo desdichado, sino como posibilidad de auto-renovación. Ella no considera los valores alternativos como momentos en un proceso histórico de la vida moral -como probablemente lo haría Hegel-, sino como interpretaciones alternativas. Y justo porque son interpretaciones, resulta imposible hacer juicios de superioridad o inferioridad entre culturas, pues cada mundo significativo conduce a una perspectiva del mundo inconmensurable con otras. Es este principio lo que ahora orienta la razón práctica hermenéutica: 1 . Esta razón práctica opera de acuerdo a los límites de cada situación particular sin aspirar a una afirmación concluyente, un saber absoluto o una precisión sistemática; 2 . La actitud de la razón práctica hermenéutica se asume como "transicional", es decir, surge como resultado de hacer elecciones comparativas respecto a otros bienes morales; 3 . El resultado de tal comparación supone una "ganancia" en la intuición moral, es decir, que su experiencia debió aportarle una mayor inteligibilidad.

Estas elecciones comparativas son esenciales si la hermenéutica quiere evadir el riesgo de caer en la falacia naturalista. Sostiene, por lo tanto, que en su encuentro con bienes alternativos, la tolerancia no conduce a actuar indiscriminadamente; por el contrario, el agente actúa haciendo discriminaciones cualitativas, es decir, haciendo explícitas las razones para actuar de tal o cual modo. Para ello recurre a dos categorías: una de raíz aristotélica, la phrónesis, y otra, propia de Charles Taylor, a la que llama "hiperbien". La phrónesis es la capacidad de discernimiento en torno a los bienes que componen nuestras vidas: es la actitud madura y serena que permite valorar aquellos estilos de vida que se consideran justos. Pero esta reflexión no opera sólo sobre las intuiciones morales propias sino sobre las intuiciones morales ajenas en función de un cierto ordenamiento de los bienes. Aquellos que obedecen a nuestra intuición moral más profunda son llamados "hiperbienes": éstos son los bienes constitutivos, los valores por los cuales ciertos bienes entran en la categoría de bienes.

A esta reflexión que el agente debe hacer acerca de los bienes, Taylor lo llama "articulación". "Articular" quiere decir interpretar aquello que es considerado un bien y simultáneamente expresarlo en la acción propia; es una interpretación-expresión que indisociablemente es instauradora de la acción y constitutiva, "reveladora" de algo que da presencia a dicho bien. Con la categoría de "articulación" la ética de inspiración hermenéutica quiere mostrar que lo decisivo es la acción moral a la vez intencional y expresiva en la que ha ejercido una crítica de sí mismo y del otro, guiada por un ordenamiento de los hiperbienes. Un individuo puede ser llamado agente moral cuando puede articular su interpretación y su expresión en una situación dada, y es sólo entonces que puede considerar haberse dado a sí mismo una identidad 
moral. Lo que finalmente caracteriza al agente moral es su capacidad de transitar de una posición moral a otra, obteniendo en este pasaje una "ganancia epistemológica":

Nos parece que la línea que va de la reflexión aristotélica sobre la prudencia, pasando por la analítica existenciaria del ser-ahí de Heidegger y la reflexión sobre la aplicación como punto central de la hermenéutica de Gadamer hasta llegar a la defensa por Taylor de una razón práctica que opera de manera comparativa y transicional y que es así el medio en que surgen articulaciones de los bienes constitutivos que instan a la acción y constituyen nuestra identidad, esta línea de pensamiento, reiteramos, es justo la que soporta la posibilidad de probar la hipótesis del trabajo entero que aquí presentamos (pp. 253-254).

A nuestro juicio, la actualidad del libro de Pablo Lazo se centra en su propósito de ofrecer una teoría hermenéutica de la acción moral que logre evadir las limitaciones de las éticas formales, procedimentales o ahistóricas. Pero esta concepción, ¿permite una comprensión completa de la acción moral? Sin pretender hacer aquí una crítica exhaustiva, deseamos señalar que parecen existir aún serias limitaciones. En efecto, observemos la definición del ser humano como un "animal auto-interpretante", que inmerso en un universo de signos lingüísticos, debe decidir la orientación de su acción eligiendo libremente entre todas las interpretaciones posibles. Debe hacer uso de su discernimiento (su phrónesis y los hiperbienes) porque todas ellas son inconmensurables entre sí. Ello se explica porque quien dice "hermenéutica" dice "interpretación", es decir, una separación inevitable entre lo representado y quien se lo representa. La hermenéutica debe su concepto de "interpretación" a su origen textual, pero ¿son las culturas "textos" ofrecidos a sus participantes? Este paso conceptual no es de ningún modo evidente. La consecuencia más notable es que esa distancia interpretativa parece cancelar la posibilidad de un verdadero conocimiento, ${ }^{1}$ al menos de tres cuestiones: a) la emergencia de los valores morales en una cultura dada; $b$ ) la manera en que esos valores persisten y son vividos por los miembros de esas comunidades, y c) la manera lenta, contrariada y conflictiva en la que esos valores se transforman, se abandonan o se revitalizan. Sin pretender que se trate de una refutación, deseamos evocar dos ejemplos contenidos en el mismo texto.

En el momento del encuentro del ritual azteca precolombino del sacrifico de las doncellas o de los guerreros enemigos, los conquistadores concluyeron,

${ }^{1}$ El capítulo II del libro se dedica justamente a sostener que las ciencias humanas no pueden escapar a ser meras interpretaciones de valores alternativos. 
con horror, que se trataba de psicópatas. "Lo que propone la hermenéutica es - por el contrario- que antes que esa precipitación al concluir es necesario... dejarse decir algo nuevo por ese fenómeno... en el duro trabajo de modificar los límites de nuestra inteligibilidad [...]" (p. 127). No encontramos adecuada tal interpretación. Desde luego el sacrificio ritual exige un conocimiento antropológico de su razón de ser, es decir, una penetración real en las condiciones de esa cultura (lo que no otorga ningún derecho de existencia al sacrificio). Para su rechazo exige igualmente - pero esto es inusual-, de parte de la cultura colonizadora, un conocimiento de sí misma que le retire la ilusión de alguna superioridad moral intrínseca y le haga consciente de que, cometiendo actos igualmente bárbaros en su presente y en su historia, tiene sin embargo razones para expresar su oposición a una práctica así. Es la emergencia histórica de valores morales que merecen respeto y que no es posible soslayar, la que permite colocar a las culturas en un plano de diálogo. En segundo lugar, dentro del mismo texto, al ofrecer su interpretación de la dialéctica del amo y el esclavo contenida en la Fenomenología del espíritu, Taylor afirma que "los deseos del amo y el esclavo entran en juego en una dinámica que ellos mismos no comprenden del todo, que llevan a cabo en una forma confusa e inarticulada", cuyo resultado es que "nuestra práctica está confundida en sus propósitos y será derrotada": "estamos comprometidos aquí con lo que será la única posible solución a este problema, es decir, la comunidad, porque incluso la institución de la relación amo-esclavo estará típicamente definida y mediada por la ley, una ley que une todas las partes y que implícitamente las reconoce como sujetos de derechos" (p. 322). Ésta es una interpretación insuficiente para comprender la emergencia y luego la intrincada, laboriosa y conflictiva tendencia a la eliminación -aún inconclusa- de la esclavitud. En ambos casos se muestra que la relación que guardan los seres humanos con sus valores morales, incluidos el sacrificio humano y la esclavitud, no es sólo la de una interpretación entre valores alternativos. La emergencia, obstinación y desaparición de los valores morales para cada cultura está entretejida de manera muy compleja con sus condiciones materiales y sociales de existencia. La cuestión central es si la concepción hermenéutica no resulta reductora de esa complejidad. La acción del ser humano tiene muchas otras dimensiones que ser dialógica, lingüística y auto-crítica. Pero dejemos ahora a la hermenéutica articular su respuesta. 